\title{
Homophones as ambiguous stimuli in research: A comparison of the associative meaning of homophones and nonhomophones
}

\author{
RUSSELL FOOTE* \\ University of Tennessee, Knoxville, Tenn. 37916
}

Thirty-six homophones and 36 nonhomophones were presented randomly to $30 \mathrm{Ss}$ in a single response, free association task. The greater dispersion of the response distributions to homophones than to nonhomophone stimuli as well as the longer response latencies to homophones suggested that the associative meaning of homophones is more ambiguous than other elements of the vocabulary and, consequently, that homophone units may be fruitfully employed in research necessitating the use of such ambiguous stimuli. Several such potential uses were discussed along with possible research aimed towards clarifying the phenomenon of homophones per se, apart from their use as research tools.

What are commonly referred to as homonyms or-more accuratelyhomophones, for some time have interested historical linguists concerned with sound change and with the effects of the semantic environment on meaning (Lehman, 1962). These pairs (or, more rarely, triplets) of words whose individual members are pronounced the same but differ both in spelling and meaning form a relatively small subset of the vocabulary of American English and are, in fact, nonexistent in some other Indo-European languages. Due to their special phonemic-semantic properties, homophones have attracted the attention of a number of psychological researchers as convenient stimulus items for use in studies dealing specifically with linguistic ambiguity or, more generally, with research requiring ambiguous verbal items for stimulus material.

Galbraith \& Taschman (1969), in research generally concerned with establishing normative data, have pointed out some of these previous and potential research uses of homophones. However, whether the focal point of the accomplished or anticipated research is perceptual encoding-decoding processes, or phonetic, semantic, subject, or contextual viriable effects, the assumption (often implicit) is that homophones are more ambiguous than nonhomophone words. Such an assumption has not, in fact, been supported empirically. As Galbraith \& Taschman point out in their article, words with multiple meanings are common in English, possibly the rule rather than the exception. In terms of the prevalent indices of word meaning employed by psychologists-such as semantic differential ratings and associative norms-there is as yet no general evidence that $S$ s respond

* Now at the University of Wyoming. Laramic. Wyo. 82070 . any differently to homophones than to other units of the vocabulary having multiple meanings. Consequently, a research question is posed which must be answered if homophones are to be used fruitfully in research as described above.

The current experiment is addressed to this question. The meaning of both homophone and nonhomophone stimuli employed in this study was defined in terms of several measures of Ss' responses to these words as they were employed as stimuli in a single-response, word association task. That is, the homophones and nonhomophones used in the study were compared on several indices of associative meaning (Deese, 1965). Further, the study was aimed at correcting a possible methodological difficulty in the Galbraith and Taschman investigation of the relative strength of the separate words within homophone units. In the free association task used by Galbraith and Taschman only homophones were used as stimuli and consequently, it was uncertain whether or not a set for homophones may have been produced in Ss, creating possible contaminating effects on their associative responses

\section{SUBJECTS}

The Ss were 30 students enrolled in introductory psychology courses at the University of Tennessee. All Ss were volunteers. The median age was 19 and both sexes were about equally represented.

$$
\text { STIMULI }
$$

A 72-word list composed of 36 homophones and 36 nonhomophones was used. Homophones were defined as pairs of words (or, infrequently, as triplets: where-wear-ware) that were identical phonemically but different in both spelling and meaning. An initial pool of 200 homophones was selected randomly from a Dictionary of American Homophones and Homographs (Whitford, 1966) and 200 nonhomophones were similarly selected from The Teacher's Word Book of 30,000 Words (Thorndike \& Lorge, 1944). From these basic pools, the 36 homophone and 36 nonhomophone stimuli were selected to reflect various combinations of frequency of occurrence in the language and of major grammatical class. This was done to control for possible effects of these variables on responses to both homophones and nonhomophone stimuli. The Thorndike-Lorge frequency count (Thorndike \& Lorge, 1944) was used to determine frequency for all stimulus words. Although these frequencies are derived from written rather than from spoken discourse, they were used in lieu of any of the few sources of spoken word frequencies (i.e., Howes, 1966) because the latter sources provide generally inadequate frequency data for homophone words, especially those of lower frequency. Grammatical (form) class for all stimulus words was determined by unanimous agreement of three independent judges-all undergraduate students-that a particular stimulus word belonged primarily in one form class. Only when all three judges agreed was a word designated as a member of a particular form class and included in the stimulus list. There was no difference in the degree of judges' agreement on homophone and nonhomophone words.

Following the above outlined procedures, 36 nonhomophone items were obtained such that 12 were of AA (high) frequency, 12 were of A (medium) frequency, and 12 were of low frequency-with each of the frequency groups containing four nouns, four verbs, and four adjectives. The 36 homophone items were selected so that the six possible combinations of the three frequency groups (high, medium, low) with two component units of each homophone pair had six individual homophone items representing them. Thus, there were six homophone items where one sense of the homophone was of high frequency and the other sense also of high frequency, six items where one sense was of high frequency and the other sense of medium frequency, and so on. Ideally, each of these frequency groups was to have consisted of equal distributions of nouns, verbs, and adjectives. However, the limited set of homophones in the language precluded all possible combinations of form classes and frequency. However, each of the major form classes used in this study was well represented among the 36 homophones. In addition, one sense of some homophones occasionally belonged to a form class other than the major three used in the experiment.

Those homophones that included past verb tenses or contractions as one or two of their different senses were generally 
Table 1

Thorndike-Lorge Frequencies and Primary Form Class for Homophones and Nonhomophones and Number of Associations to Different Homophone Senses

\begin{tabular}{|c|c|c|c|c|c|c|c|c|c|}
\hline \multicolumn{7}{|c|}{ Homopinones } & \multicolumn{3}{|c|}{ Nonhomophones } \\
\hline Homophone Lnits & \multicolumn{2}{|c|}{$\begin{array}{c}\mathrm{T}-\mathrm{L} \\
\text { Frequencies }\end{array}$} & \multicolumn{2}{|c|}{$\begin{array}{c}\text { Primary } \\
\text { Form Class } \\
\end{array}$} & \multicolumn{2}{|c|}{$\begin{array}{l}\text { Number of } \\
\text { Associations }\end{array}$} & \multirow[b]{2}{*}{ Nord } & \multirow{2}{*}{$\begin{array}{c}\text { T-L } \\
\text { Frequencies }\end{array}$} & \multirow{2}{*}{$\begin{array}{c}\text { Primary } \\
\text { Fom } \\
\text { Class }\end{array}$} \\
\hline$A$ & A & $\mathrm{B}$ & A & $\mathrm{B}$ & A & B & & & \\
\hline 1. meat-meet* & $\mathrm{AA}$ & AA & $N$ & $\mathrm{~V}$ & 24 & 4 & 1. law & $A A$ & $\mathrm{~N}$ \\
\hline 2. wear-where* & $\mathrm{AA}$ & $\mathrm{AA}$ & $\mathbf{V}$ & 0 & 27 & 0 & 2. voice & $\mathrm{AA}$ & $\mathbf{N}$ \\
\hline 3. son-sun* & $\mathrm{AA}$ & $\mathrm{AA}$ & $N$ & $\mathrm{~N}$ & 7 & 22 & 3. ball & $\mathrm{AA}$ & $\mathrm{N}$ \\
\hline 4. scene-seen & $\mathrm{AA}$ & AA & $\mathrm{N}$ & $\mathrm{V}$ & 15 & 10 & 4. heaven & $\mathrm{AA}$ & $N$ \\
\hline 5. write-right & AA & AA & $\mathbf{V}$ & $\mathrm{Aj}$ & 9 & 20 & 5. red & $\mathrm{AA}$ & $\mathrm{Aj}$ \\
\hline 6. whole-hole* & $A A$ & AA & $\mathrm{Aj}$ & $N$ & 4 & 18 & 6. old & $A A$ & $\mathrm{Aj}_{\mathrm{j}}$ \\
\hline 7. week-weak* & AA & A & $N$ & $\mathrm{Aj}$ & 4 & 26 & 7. heavy & $\mathrm{AA}$ & $\mathrm{Aj}$ \\
\hline 8. plain-plane & $\mathrm{AA}$ & A & $\mathrm{Aj}$ & $\mathrm{N}^{2}$ & 6 & 22 & 8. deep & AA & $\mathrm{Aj}$ \\
\hline 9. sail-sale & $\mathrm{AA}$ & $A$ & $\mathrm{~N}$ & $\mathbf{N}$ & 17 & 11 & 9. open & AA & $\mathrm{V}$ \\
\hline 10. some-sum & $\mathrm{AA}$ & A & $\mathrm{Aj}$ & $\mathbf{N}$ & 20 & 10 & 10. consider & AA & $\mathrm{V}$ \\
\hline 11. be-bee* & $\mathrm{AA}$ & A & $\mathrm{V}$ & $\mathbf{N}$ & 4 & 20 & 11. travel & AA & V \\
\hline 12. bear-bare & AA & A & $\mathbf{N}$ & $\mathrm{Aj}$ & 16 & 11 & 12. build & AA & $\mathrm{V}$ \\
\hline 13. him-hymn* & $\mathrm{AA}$ & other & $\mathbf{N}$ & $N^{2}$ & 21 & 7 & 13. anger & A & $\mathbf{N}$ \\
\hline 14. waste-waist* & AA & other & $N$ & $N$ & 23 & 4 & 14. dawn & A & $\mathrm{N}$ \\
\hline 15. beat-beet $*$ & AA & other & $v$ & $\mathrm{~N}$ & 28 & 0 & 15. religion & A & $\mathbf{N}$ \\
\hline 16. break-brake* & $\mathrm{AA}$ & other & $V$ & $\mathrm{~N}$ & 29 & 0 & 16. net & A & $\mathbf{N}$ \\
\hline 17. dear-deer* & $\mathrm{AA}$ & other & $\mathrm{Aj}$ & $\mathrm{N}$ & 5 & 23 & 17. slow & A & $\mathrm{Aj}$ \\
\hline 18. so-sew* & $\mathrm{AA}$ & other & 0 & $\mathrm{~V}$ & 2 & 27 & 18. wet & A & $\mathrm{Aj}$ \\
\hline 19. tail-tale* & A & A & $\mathrm{N}$ & $\mathrm{N}$ & 21 & 4 & 19. loud & A & $\mathrm{Aj}$ \\
\hline 20. principle-principal & A & $\mathrm{A}$ & $\mathbf{N}$ & $\mathrm{N}$ & 7 & 20 & 20. sad & A & $\mathbf{A j}$ \\
\hline 21. worn-warn & A & A & $\mathrm{Aj}$ & $\mathrm{V}$ & 11 & 16 & 21. hìt & A & $\mathrm{V}$ \\
\hline 22. steal-steel*. & A & A & $\mathrm{V}$ & $\mathrm{N}$ & 22 & 6 & 22. jump & A & $\mathrm{V}$ \\
\hline 23. stare-stair* & $A$ & A & $\mathrm{V}$ & $\mathrm{N}$ & 27 & 2 & 23. glow & A & $\mathrm{V}$ \\
\hline 24. wheel-we'll & $\mathrm{A}$ & A & $\mathrm{N}$ & $\mathrm{O}$ & 27 & 0 & 24. hide & A & $\mathrm{V}$ \\
\hline 25. heel-heal & A & other & $\mathrm{N}$ & $\mathrm{V}$ & 18 & 9 & 25. candy & other & $\mathbf{N}$ \\
\hline 26. birth-berth* & $\mathrm{A}$ & other & $N$ & $\mathrm{~N}$ & 28 & 0 & 26. insect & other & $\mathbf{N}$ \\
\hline 27. aunt-ant* & A & other & $N$ & $\mathrm{~N}$ & 3 & 26 & 27. divorce & other & $\mathrm{N}$ \\
\hline 28. mail-male & $A$ & other & $\mathrm{N}$ & $\mathbf{N}$ & 10 & 16 & 28. snail & other & $\mathrm{N}$ \\
\hline 29. bore-boar & A & other & $\mathrm{V}$ & $\mathrm{N}$ & 17 & 7 & 29. sour & other & $\mathrm{Aj}$ \\
\hline 30. load-lode* & A & other & $N$ & $\mathrm{~N}$ & 25 & 0 & 30. somber & other & $\mathrm{Aj}$ \\
\hline 31. altar-alter & other & other & $\mathrm{N}$ & $\mathrm{V}$ & 14 & 15 & 31. swift & other & $\mathrm{Aj}$ \\
\hline 32. bridal-bridle & other & other & $\mathrm{Aj}$ & $\mathbf{N}$ & 16 & 12 & 32. innocent & other & $\mathrm{Aj}$ \\
\hline 33. dual-duel & other & other & $\mathbf{A j}$ & $\mathrm{N}$ & 8 & 20 & 33. chase & other & $\mathrm{V}$ \\
\hline 34. mantle-mantel* & other & other & $\mathrm{N}$ & $\mathbf{N}$ & 4 & 23 & 34. rob & other & V \\
\hline 35. loan-lone & other & other & $\mathrm{N}$ & $\mathrm{Aj}$ & 21 & 8 & 35. starve & other & $\mathrm{V}$ \\
\hline 36: foul-fowl & other & other & $\mathrm{Aj}$ & $N^{*}$ & 13 & 15 & 36. decorate & other & V \\
\hline
\end{tabular}

$a_{Y}=$ noun, $Y=$ lerb, $A j=$ adjective, $O=$ other

*Indicates significant difference in proportionts of responses received, $p<.05$.

a voided. Similarly, homophones were avoided in which one or both senses were obscure words or proper nouns. The pair wheel-we'll, however, was included as an exception. Also, despite preexperimental proofreading of the stimulus list by the author and at least six other people, a homophone, red-read, appeared among those designated as nonhomophone items. Since all Ss' responses to this stimulus were related to the color sense and none to the sense of the verb's past tense, and since the responses indicated no temporal pattern distinct from other nonhomophones, it was felt that the item could be effectively regarded as a nonhomophone stimulus.

Table 1 presents the 72 .stimulus items and includes information regarding frequency and form class as well as information to be discussed in the results below.

\section{PROCEDURE}

All Ss were presented the 72 stimulus items-in a different random order for each $\mathrm{S}$-in a single-response free-association task. Words were presented aurally to Ss who were asked to respond with one word, the first word which came to mind, as rapidly as possible. Responses were made by Ss into a microphone which was visible to $S s$ and which was attached to a Wollensak stereophonic tape recorder. After Ss left the experimental room, the recorded responses were used to actuate the pen of a single-channel Techni-rite heat writing oscillograph (Model 4) with chart paper moving at the rate of $10 \mathrm{~mm} /$ minute. After the recording had been made on chart paper, the tape was replayed to coordinate each deflection of the oscillograph pen with an associative response by $S$. Consequently, a temporal as well as a verbal record of each S's response was obtained.

\section{RESULTS AND DISCUSSION}

Three independent judges (not the same individuals involved in form class judgments described above) assigned Ss' responses to homophones to one of a homophone's two major senses or, if conditions to be described below prevailed, to neither sense. The numbers in the two columns under the heading Number of Associations in Table 1 present the number of times that the judges agreed unanimously that $S$ 's response to a homophone belonged to one or the other of the homophone's two major senses. When there was not unanimous agreement, when a response was uninterpretable, or when there was no response by $S$, no assignment was made. Of $1,080(30 \times 36)$ possible responses to homophones, only 38 could not be assigned to one or the other major senses of a homophone because of failure to achieve unanimous agreement among judges. As an example, Table 1 indicates that 24 Ss were judged to have given associative responses to the meat sense of the first homophone pair shown in the table, 4 Ss were judged to have responded to the meet sense, leaving two responses not assigned by the judges to either sense of the homophone.

Of the 23 homophone pairs used in both the present experiment and the work reported by Galbraith \& Taschman (1969), inspection of the proportion of 
frec-associative responses given to each sense of these pairs reveals that only in the case of scene-seen are the proportions obiained in the present rescalch $(.60$ and 40. respectively) opposite to that obtained in the earlier experiment $(.43$ and .53 , respectively). Since neither of these proportions differs significantly from $.50-.50$, however, this difference may be attributed to chance. In the other 22 pairs, where the direction of the proportions are the same in both experiments, the magnitudes of the differences in proportions between the present study and the results of Galbraith and Taschman may likewise be attributed to chance or to consistent differences in experimental procedure (i.e., use of homophone stimuli exclusively vs a $\mathrm{mixed}$ homophone-nonhomophone list or differences in judgments in assigning Ss' responses to one or the other sense of the mutually used homophone stimuli). In general, however, the results are quite comparable.

To investigate the hypothesis that homophones, when used as stimuli in a word-association task, tend to elicit patterns of responses indicative of more stimulus ambiguity than do nonhomophones, analyses were made comparing the response distributions to homophones and nonhomophones used in the present experiment. Two frequently employed measures of the degree of ambiguity of the associative meaning of verbal stimuli are percentage of the primary (most frequently occurring) response in response distributions to such stimuli and the number of different (non repeated) responses occurring in distributions of total responses to such stimuli (Cramer, 1968; Deese, 1965). To assess differences between homophones and nonhomophones on the percentage of primary responses produced, a median chi-square test was performed. For homophones the percentage of the primary response in the separate response distributions to 13 homophone stimuli exceeded the overall stimulus list median prinary response percentage of 34.2 , and the primary response percentage of the other 23 separate homophona response distributions fell below this median. The results were 22 and 14 , respectively, for nonhomophones. The results of this test yielded a $\chi^{2}(1)$ of $4.50, p<.05$. Similarly, a median chi-square test was made comparing homophone and nonhomophone stimuli in terms of the number of different responses in each of the distributions of total responses to each of the stimulus words. Although homophones tended to yield more different responses per distribution (median of 14.5 vs median of 11.5) than did nonhomophones, this result reached significance only at $p<.20, x^{2}(1)=3.75$. Nevertheless, this result, taken together with the result concerning differences between homophones and nonhomophones on the percentage of the primary response, seems to indicate a definite tendency in the response distributions to homophone stimuli toward more dispersion than in the response distributions to nonhomophones.

The evidence for differences in the degree of ambiguity of the associative meaning between homophones and nonhomophones is furthered by consideration of the marked difference in Ss' response latencies to homophones and nonhomophones--where response latency was defincd as the time between offset of the stimulus word and onset of S's response. When individual $\mathrm{Ss}^{\prime}$ mean response time to the 36 homophones was compared to their mean response time to the 36 nonhomophones, it was found that 26 of the $30 \mathrm{Ss}$ took longer, on the average, to respond to homophones. A two-tailed sign test showed this difference to be significant, $p<.001$. The overall mean response latency to homophones was $1.85 \mathrm{sec}$ and for nonhomophones was $1.52 \mathrm{sec}$; the SDs were .11 and .10, respectively. For those four Ss whose mean response latency was higher for nonhomophones, the magnitude of the difference was never larger than .11 sec. For those Ss who took longer to respond to homophones, the magnitude of this greater mean latency ranged from .11 to $.81 \mathrm{sec}$ for the $26 \mathrm{Ss}$.

The results of the present experiment suggest that it is feasible to regard homophones as relatively ambiguous stimuli for use in research calling for such ambiguous stimulus material, at least to the extent that the associative meaning of homophones reflects the general semantic ambiguity of these word pairs and triplets. Together with the normative data collected by Galbraith \& Taschman (1969), this finding should allow wider use of these relatively unique linguistic structures as useful research tools. In addition to the potential uses mentioned by Galbraith and Taschman and in the beginning of this paper, these stimuli seem particularly well suited for research on such phenomena as category clustering when they are used as stimuli in continuous association and recall tasks. Because only homophones, among al words of multiple meaning in the English vocabulary, have their distinet semantic senses demarcated graphemically into two or more different words, an additional, unique research potential for homophones is suggested in relating spoken language and its written representation.

Along with these research uses of homophones, the homophone per se merits further experimental investigation. It is far from clear why one semantic sense of a homophone should overshadow the other in $S^{\prime}$ 's immediate responding to these stimuli. Possibly, an experimental task which allows Ss to give continuous association to homophones may clarify the relationship between elements of homophone pairs and help to explain why one sense should consistently dominate the other when a homophone is encountered out of linguistic context. Certainly, semantic contextual effects are the most likely source of disambiguity of homophones in day-to-day speech. Nevertheless, as the wide occurrence of linguistic puns will attest, the ambiguity of homophones can be comfortably entertained and even courted in speech. The question arises that under what conditions does a langiage community tolerate the existence of a small subset of its total vocabulary which allows the possibility of such ambiguity? An interesting suggestion offered by some historical linguists and dialect geographers (Lehman, 1962) is that such members are tolerated in the most widely used vocabulary of a language community at a particular time to the extent that their different semantic senses are part of sharply distinct semantic environments: A homophone whose two senses referred to two closely related parts of the body, for example, would have little chance of survival; a synonym for one or the other sense, some linguists have pointed out, generally comes to take the place of one of the senses of the homophone. Clearly, research which would clarify the roll of the semantic environment in the establishment, perpetuation, and disambiguation of homophones is called for.

\section{REFERENCES}

CRAMER, P. Word association. New York: Academic Press, 1968.

DEESE, J. The structure of associations in language and thought. Baltimore: Johns Hopkins Press, 1965.

GALBRAITH, G., \& TASCHMAN, C. Homphone units: A normative and methodological investigation of the strength of component elements. Journal of Verbal Learning \& Verbal Behavior, 1969, 8, 737-744.

HOWES, D. A word count of spoken English. Journal of Verbal Learning \& Verbal Behavior, $1966,5,572-604$.

LEHMAN, W. Historical linguistics: An introduction. New York: Holt, Rinehart, \& Winston, 1962.

THORNDIKE, E., LORGE, I. The teacher's word book of 30,000 words. New York: Bureau of Publications, Teachers College, Columbia University, 1944.

WHITFORD, H. A dictionary of American homophones and homographs. New York: Bureau of Publications, Teachers College, Columbia University, 1966. 